\title{
Preparation and Evaluation of Sustained-Release Doxazosin Mesylate Pellets
}

\author{
Jung-Myung Ha, ${ }^{a}$ Ju-Young Kim, ${ }^{a}$ Tack-Oon Oh, ${ }^{a}$ Yun-Seok Rhee, ${ }^{b}$ Sang-Cheol Chi, ${ }^{a}$ \\ Hyon Kuk, ${ }^{a}$ Chun-Woong Park, ${ }^{*, c}$ and Eun-Seok Park ${ }^{*, a}$ \\ ${ }^{a}$ School of Pharmacy, Sungkyunkwan University; 300 Cheoncheon-dong, Jangan-gu, Suwon, Gyeonggi-do 440- \\ 746, Republic of Korea: ${ }^{b}$ College of Pharmacy and Research Institute of Pharmaceutical Sciences, Gyeongsang \\ National University; Jinju, Gyeongnam 660-751, Republic of Korea: and ${ }^{c}$ College of Pharmacy, Chungbuk National \\ University; 410 Seongbong-ro, Heungdeok-gu, Cheongju, Chungbuk 361-763, Republic of Korea. \\ Received August 31, 2012; accepted January 23, 2013; advance publication released online February 4, 2013
}

\begin{abstract}
Doxazosin mesylate (DXM) sustained release pellets were prepared by an extrusion-spheronization and fluid-bed coating technique. The core pellets containing DXM were prepared by extrusion-spheronization technique, and coated by a fluid-bed coater to control the release of DXM. The factors affecting to properties of pellets, such as diluent content, type and coating level of coating agents and plasticizers were studied in the present study. Polymethacrylate derivatives (Eudragit ${ }^{\circledR}$ RS PO and RL PO) were used for coating agents, and polyethylene glycol 6000 (PEG 6000), triethyl citrate (TEC) and castor oil were as plasticizers. To evaluate the properties of prepared pellets, the size of prepared pellets was investigated by sieve analysis technique and the morphology of pellets was evaluated by scanning electron microscopy. Through the dissolution test, factors that have an effect on the dissolution of the drug were evaluated. As the content ratio of microcrystalline cellulose (MCC) had increased, the dissolution was proportionally sustained. Eudragit ${ }^{\circledR}$ RS PO had more marked sustaining effect on the dissolution rate than Eudragit ${ }^{\circledR}$ RL PO, and the effect was more pronounced with the increased coating level. PEG 6000 was an appropriate plasticizer for DXM pellets, and increasing the content of PEG 6000, was also slightly decreasing the dissolution rate.
\end{abstract}

Key words sustained release; pellet; extrusion-spheronization; fluid-bed coating; doxazosin mesylate

Doxazosin mesylate (DXM) is a selective inhibitor of $\alpha_{1}$-adrenergic receptors and has been demonstrated to be effective for the treatment of hypertension and benign prostatic hyperplasia. ${ }^{1-3)}$ DXM lowers the blood pressure of hypertensive patients by blocking postjunctional $\alpha_{1}$-adrenergic receptors, and then systemic vascular resistance decreases. ${ }^{4)}$ Taking a DXM can cause first-dose side effects like hypotension because of the rapid increase of drug concentration in the blood. ${ }^{5)}$ Therefore the usual therapy of DXM is initially starting with a low dose $(1 \mathrm{mg} / \mathrm{d})$ and gradually increased up to the daily maximum recommended dose $(16 \mathrm{mg} / \mathrm{d}){ }^{2)}$ In order to overcome the adverse effects of DXM and to improve inconvenience of the regimen, various studies for controlled-release dosage forms of DXM have been conducted. ${ }^{6-8)}$

Application of the controlled release system to DXM could have benefits such as reducing the adverse effects by minimizing the fluctuation of drug concentration in the plasma. DXM could cause a significant reduction in blood pressure after administration of the first dose, so a formulation of sustained release of DXM could avoid this first dose effect. Among several systems for controlled release of the model drug, multi-unit dosage forms such as pellets or beads coated with polymers used as a release retardant has several advantages. The single unit dosage form like tablets has been widely used because of its simple and cost-effective manufacturing operations and ease of administration. ${ }^{9,10)}$ In comparison with a single unit dosage form, the multi-unit dosage form has numerous advantages. ${ }^{11-15)}$ At first, it could be dispersed freely in the gastrointestinal tract, and thereby it could maximize drug absorption, and reduce peak plasma fluctuation. Secondly, when formulated in sustained-release dosage forms, it is less

The authors declare no conflict of interest. susceptible to dose dumping than single unit formulations, and also offers the advantage of flexibility for the development of a multi-unit dosage form which contains more than one active pharmaceutical ingredient. Pellets containing different drugs can be packed in a capsule and administered at one time conveniently.

The extrusion-spheronization technique has been most widely used in the preparation of spherical pellets. ${ }^{16-18)}$ The extrusion-spheronization technique involves four preparation steps: mixing, kneading, extrusion, spheronization. The pellets prepared by this technique show a spherical shape and highly dense property, so they have good flowability that enables high loading of drug.

The coating of pellets for the sustained release of drugs is one of the numerous advances in the formulation of sustainedrelease drugs. ${ }^{19,20)}$ The benefits of sustained release and multi-unit dosage forms could be achieved by this technique. It allows for a decrease of dosing frequency, minimizes side effects and ensures good dispersion throughout the gastrointestinal tract.

In the present study, DXM pellets that consist of microcrystalline cellulose, lactose monohydrate and dibasic calcium phosphate as a matrix were prepared by extrusion-spheronization technique. In order to control the release of DXM from pellets, a polymer coating process by fluid-bed coater was performed. The objective of this study is to formulate sustainedrelease coated pellets containing DXM and to evaluate the properties of pellets according to formulation factors.

\section{Experimental}

Materials DXM, the active pharmaceutical ingredient, was obtained from Jiangsu Medicines and Health Products Co., China. Microcrystalline cellulose (MCC, Comprecel ${ }^{\circledR}$ 
M-101, Mingtai Chemical Co., Taiwan) and Lactose monohydrate (DMV International, the Netherlands) were used as a diluent, and polymethacrylate derivatives Eudragit $^{\circledR}$ RS PO, RL PO, Evonik Industries AG, Germany) were used for a coating agent. Polyethylene glycol 6000 (PEG 6000, Shinyo Pure Chemical Co., Japan), castor oil (Shinyo Pure Chemical Co., Japan) and triethyl citrate (TEC, Aldrich Chemical Co., U.S.A.) were used as a plasticizer.

Preparation of DXM Core Pellets The DXM core pellets were prepared by the extrusion-spheronization technique and the formulations of core pellets are given in Table 1. The pellets prepared from MCC have a hard nature and are difficult to break, ${ }^{21-23)}$ so MCC is suitable for the diluent of matrix pellets. The pellets were prepared by a wet granulation method. At first, the model drug, DXM, and other additives were blended in a polyethylene vinyl bag for $5 \mathrm{~min}$. The resultant mixture was kneaded with the addition of a binder solution to make a wet mass. For the binder solution, povidone K30 dissolved in $30 \%$ ethanol was used, and povidone K30 was then included in pellets with a ratio of $1.5 \%$ consequentially. The wet mass was passed through a twin-screw extruder (Model P-60, Kwangi, Korea; MG-55, Dalton, Japan) equipped with the $1 \mathrm{~mm}$ screen. The extrudates were processed in the spheronizer (Model E-210, Kwangi, Korea; QJ-230T, Dalton, Japan) fitted with a cross-hatched plate rotating at $500 \mathrm{rpm}$ for $10 \mathrm{~min}$. After spheronization process, the prepared pellets were dried in an oven at $50^{\circ} \mathrm{C}$ for $4 \mathrm{~h}$.

Preparation of DXM Coated Pellets To control dissolution rate of DXM from the pellets, the core pellets prepared by extrusion-spheronization technique were coated with a coating dispersion containing Eudragit ${ }^{\circledR}$ RL PO/RS PO and other ingredients using a fluid-bed coater (Model D-7852, Glatt
$\mathrm{GmbH}$, Germany) equipped with a bottom spray device.

Preparation of Coating Dispersion The coating dispersion was prepared according to the composition presented in Table 2. Eudragit ${ }^{\circledR}$ RL PO and RS PO were used as coating agent mainly to control dissolution rate of the drug. PEG 6000, TEC and castor oil were screened for plasticizer, and talc was used as an anti-tacking agent. The procedure to prepare the coating dispersion was as in the following. At first, the coating agent (Eudragit ${ }^{\circledR}$ RL PO or RS PO) was dissolved in the mixture of isopropyl alcohol and acetone $(3: 2$, w/w) with a mechanical stirrer (Model RW 20 DZM, IKA ${ }^{\circledR}$-Labortechnik Co., Germany), and then distilled water was poured into the solution up to the desired ratio (mixture of organic solventswater $=2: 3, \mathrm{w} / \mathrm{w}$ ) with stirring. Then, other ingredients were added to the coating solution, and stirred homogeneously.

Coating of DXM Core Pellets The core pellets containing DXM were coated with prepared coating dispersion by a fluid-bed coater in the following manner. First, $450 \mathrm{~g}$ of DXM core pellets were put into the coating chamber of fluid-bed coater. The coating dispersion was pumped into the fluidbed coater constantly by a peristaltic pump (MP-3, EYELA, Japan). The core pellets were coated with a coating dispersion to reach the predetermined coating level, 2.5, 5, 7.5, 10, 12.5, 15 and $17.5 \%$ as weight gain. The operation parameters of the fluid-bed coater and the setting conditions for coating are given in Table 3. After finishing the coating process, the prepared pellets were cured in an oven at $50^{\circ} \mathrm{C}$ for $4 \mathrm{~h}$.

Size Distribution of the DXM Pellets The size distribution of the pellets was evaluated by a sieve analysis technique $\mathrm{e}^{24,25)}$ using US standard sieves with 1400, 1000, $850,710,500 \mu \mathrm{m}$ opening size (Chung Gye Inc., Korea). Pellets was put on the sieve with the largest mesh size and

Table 1. Formulations Used for the Preparation of DXM Core Pellets Using Extrusion-Spheronization Method (Unit: mg)

\begin{tabular}{|c|c|c|c|c|}
\hline \multirow{2}{*}{ Ingredients } & \multicolumn{4}{|c|}{ Formulations } \\
\hline & DP1 & DP2 & DP3 & DP4 \\
\hline Doxazosin mesylate & 5.1 & 5.1 & 5.1 & 5.1 \\
\hline Microcrystalline cellulose & 210 & 150 & 90 & 30 \\
\hline Lactose monohydrate & 14.4 & 74.4 & 134.4 & 194.4 \\
\hline $\begin{array}{l}\text { Dibasic calcium phosphate } \\
\text { dihydrate }\end{array}$ & 60 & 60 & 60 & 60 \\
\hline Talc & 6 & 6 & 6 & 6 \\
\hline Polyvinylpyrrolidone K30 & 4.5 & 4.5 & 4.5 & 4.5 \\
\hline Total & 300 & 300 & 300 & 300 \\
\hline
\end{tabular}

Table 2. Formulations of Coating Dispersion Employed for Coating of DXM Core Pellets with Fluid-Bed Coater (Unit: g)

\begin{tabular}{|c|c|c|c|c|c|c|c|c|c|c|c|}
\hline \multirow{2}{*}{ Ingredients } & \multicolumn{11}{|c|}{ Formulations } \\
\hline & $\mathrm{CP} 1$ & $\mathrm{CP} 2$ & $\mathrm{CP} 3$ & $\mathrm{CP} 4$ & $\mathrm{CP} 5$ & CP6 & $\mathrm{CP} 7$ & $\mathrm{CP} 8$ & СР9 & $\mathrm{CP} 10$ & CP11 \\
\hline $\begin{array}{c}\text { Eudragit }^{\circledR} \\
\text { RS PO }\end{array}$ & 80 & 80 & 80 & 80 & - & - & - & - & 80 & 80 & 80 \\
\hline $\begin{array}{c}\text { Eudragit }^{\circledR} \\
\text { RL PO }\end{array}$ & - & - & - & - & 80 & 80 & 80 & 80 & - & - & - \\
\hline Castor oil & - & 8 & - & - & - & 8 & - & - & - & - & - \\
\hline $\begin{array}{l}\text { Triethyl } \\
\text { citrate }\end{array}$ & - & - & 8 & - & - & - & 8 & - & - & - & - \\
\hline PEG 6000 & - & - & - & 8 & - & - & - & 8 & 4 & 16 & 24 \\
\hline Talc & 26.7 & 26.7 & 26.7 & 26.7 & 26.7 & 26.7 & 26.7 & 26.7 & 26.7 & 26.7 & 26.7 \\
\hline
\end{tabular}

The total volume of coating solution was $800 \mathrm{~mL}$ for each formulations and it was comprised of $320 \mathrm{~mL}$ of organic solvents (mixture of isopropyl alcohol and acetone with ratio of $3: 2$ ) and $480 \mathrm{~mL}$ of water. 
Table 3. Operation Parameters of the Fluid-Bed Coater during the Coating of Core Pellets

\begin{tabular}{lc}
\hline \hline Operation parameters & Setting conditions \\
\hline Loading amounts & $450 \mathrm{~g}$ \\
Solution spray rate & $6.12-7.76 \mathrm{~g} / \mathrm{min}$ \\
Nozzle diameter & $0.8 \mathrm{~mm}$ \\
Atomizing spray air pressure & $1.5 \mathrm{bar}$ \\
Exhaust air flap & $0.4-0.5 \mathrm{bar}$ \\
Inlet temperature & $25-30^{\circ} \mathrm{C}$ \\
Spray time & $40 \mathrm{~s}$ \\
Back filter shaking time & $2 \mathrm{~s}$ \\
\hline
\end{tabular}

shaken consistently. After shaking, the number of pellets that remained on each of the sieves were measured and plotted.

Morphology of DXM Pellets The surface morphology of the DXM core pellets and that of the coated pellets by coating dispersions were examined by scanning electron microscopy (SEM, JSM-35CF, Jeol, Japan). The core and coated pellets were placed on a double-faced adhesive carbon tape attached to a metal stub, and then coated with platinum using a sputter (Model E5200, U.K.) at $50 \mathrm{~mA}$ for about $120 \mathrm{~s}$. The apparent shape and surface morphology of the core and coated pellets were examined at a magnification ratio of $\times 100$ and $\times 1000$, respectively. The cross-section morphology of the coated pellets was examined to confirm the uniform thickness of the coating layer at a magnification ratio of $\times 400$ by the process mentioned above.

In Vitro Dissolution Studies The dissolution rates of DXM from core pellets (or coated pellets) were measured using an USP apparatus 2 (DST-600A, Labfine Inc., Korea) at $37 \pm 0.5^{\circ} \mathrm{C}$ at a stirring rate of $75 \mathrm{rpm}$. The dissolution medium was simulated with gastric fluids without enzymes $(\mathrm{pH}$ 1.2). Also, $8 \mathrm{~mL}$ of the sample medium was withdrawn and an equal volume of the test medium was replaced at each sampling time, $0.5,1,2,4,6,8$, and $16 \mathrm{~h}$. The acquired sample mediums were filtered immediately through a syringe filter (0.45 $\mu \mathrm{m}$ NYL filter, Whatman, U.K.). All experiments were done in triplicate and the filtrated samples were diluted by a mobile phase before HPLC analysis.

The amount of the drug released from the pellets was analyzed by a slightly modified validated HPLC method ${ }^{26)}$ using the HPLC system (7000 series, Hitachi Ltd., Japan). The column used was a Luna C18 column $(5 \mu \mathrm{m}, 150 \mathrm{~mm} \times 4.6 \mathrm{~mm}$, Phenomenex, U.S.A.). The mobile phase was a mixture of a $0.05 \mathrm{M}$ phosphate buffer $(\mathrm{pH} 4.8)$ and acetonitrile (in the volume ratio of $2: 1$ ), and its flow rate was $1 \mathrm{~mL} / \mathrm{min}$. The detection wavelength was fixed at $246 \mathrm{~nm}$.

The release kinetic parameters of prepared pellets were calculated through various release kinetic models to confirm the release mechanism of DXM from pellets. The equations used in the study are expressed as follows:

Zero-order equation $^{27)}$.

$$
Q_{t}=k_{0} \cdot t
$$

where $Q_{t}$ is the amount of drug released in time $t$, and $k_{0}$ is zero-order release constant.

First-order equation $^{28)}$ :

$$
\log Q_{t}=\log Q_{0}+\frac{k_{1} \cdot t}{2.303}
$$

where $k_{1}$ is first-order release constant. Higuchi's equation $^{29)}$ :

$$
Q_{t}=k_{\mathrm{H}} \cdot t^{1 / 2}
$$

where $k_{\mathrm{H}}$ is Higuchi dissolution constant.

Hixson-Crowell equation ${ }^{30)}$ :

$$
Q_{0}^{1 / 3}-Q_{t}^{1 / 3}=k_{\mathrm{HC}} \cdot t
$$

where $k_{\mathrm{HC}}$ is Hixson-Crowell dissolution constant.

The calculated kinetic parameters from above equations are shown in Tables 4 and 5.

\section{Results and Discussion}

Size Distribution of DXM Pellets The size and size distribution of the core pellets containing 50\% MCC was evaluated by the sieve analysis technique. The frequency (\%) of pellets remaining on each mesh size sieve versus mesh size was plotted in Fig. 1. As the sum of the frequency of core pellets between 1410 and $707 \mu \mathrm{m}$ used for coating was $84.02 \%$, it appeared that the extrusion-spheronization technique used was adequate to prepare DXM core pellets for coating.

Morphology of DXM Pellets The scanning electron micrographs of DXM core pellets are shown in Figs. 2a and b. As a result, the core pellets were shown to have a regular spherical shape and slightly rough surface. The pellets coated by fluid-bed coater were also examined. The coated pellets were cross-sectioned and the coating layers were observed. The morphology of cross-sectioned pellets coated with Eudragit $^{\circledR}$ RS PO at a coating ratio of 2.5 and $17.5 \%$ was shown in Figs. 2c and d. The uniform coating layer was observed at both ratios and the coating layer got thicker as the coating ratio increased (white circles). Therefore, it was confirmed that DXM pellets were coated successfully and the coating process by fluid-bed coater was appropriate for subsequent experiments.

To evaluate the effect of plasticizers on the coating layer property, pellets coated with various plasticizers, PEG 6000, TEC and castor oil, were observed by scanning electron microscope (SEM) and shown in Figs. 2e-g. The pellets coated with PEG 6000 or TEC as a plasticizer, showed a smooth surface and the coating layer was well formed. On the other hand, the pellets coated with castor oil showed cracks on the surface, and it seemed the coating layer could not be formed perfectly.

Effect of Content of MCC in Core Pellets on Dissolution Rate MCC and lactose were used as fillers for the matrix composition of core pellets. In the present study, the dissolution rate of DXM from core pellets containing different amounts of MCC $(10,30,50,70 \%)$ was evaluated and the decreased amount of MCC was substituted by lactose. The formulation of the core pellet formulation is shown in Table 1 .

The dissolution profiles showed that as the content ratio of MCC increased, the dissolution rate decreased. Figure 3 shows the dissolution profile of DXM from core pellets containing different amounts of MCC. It could be confirmed distinctly from the kinetic constant plotted. The kinetic constant was calculated by first-order equation, which showed most well fitted among several release kinetic equations (Table 4). According to the results, when the content of MCC had increased 10 to $70 \%$, the kinetic constant had decreased. The decline of the kinetic constant means a decrease in the drug release rate. 
Table 4. Kinetic Parameters of Doxazosin Mesylate Pellet Formulations

\begin{tabular}{|c|c|c|c|c|c|c|c|c|}
\hline \multirow{2}{*}{$\begin{array}{l}\text { Formulation } \\
\text { code }\end{array}$} & \multicolumn{2}{|c|}{ Zero-order } & \multicolumn{2}{|c|}{ First-order } & \multicolumn{2}{|c|}{ Higuchi } & \multicolumn{2}{|c|}{ Hixson-Crowell } \\
\hline & $R^{2}$ & $K$ & $R^{2}$ & $K$ & $R^{2}$ & $K$ & $R^{2}$ & $K$ \\
\hline DP1 & 0.8533 & 4.5229 & 0.9880 & 0.1212 & 0.9708 & 22.8214 & 0.9568 & 0.1313 \\
\hline DP2 & 0.9051 & 7.6731 & 0.9872 & 0.1946 & 0.9749 & 28.4005 & 0.9679 & 0.2171 \\
\hline DP3 & 0.8389 & 7.8976 & 0.9764 & 0.2597 & 0.9342 & 29.7220 & 0.9416 & 0.2625 \\
\hline DP4 & 0.8335 & 13.0788 & 0.9675 & 0.4758 & 0.9207 & 37.9509 & 0.9319 & 0.4670 \\
\hline $\mathrm{CP} 1^{a)}$ & 0.8321 & 4.7978 & 0.9681 & 0.1145 & 0.9593 & 24.3707 & 0.9310 & 0.1294 \\
\hline $\mathrm{CP} 2^{a)}$ & 0.9260 & 4.7433 & 0.9945 & 0.0901 & 0.9927 & 23.2343 & 0.9797 & 0.1108 \\
\hline $\mathrm{CP}^{a}{ }^{a}$ & 0.9430 & 5.1703 & 0.9990 & 0.0383 & 0.9713 & 13.3550 & 0.9997 & 0.0536 \\
\hline $\mathrm{CP} 4^{a}{ }^{a}$ & 0.9958 & 2.8584 & 0.9997 & 0.1103 & 0.9973 & 25.1542 & 0.9944 & 0.1294 \\
\hline $\mathrm{CP}^{b)}$ & 0.9771 & 9.3038 & 0.9996 & 0.1570 & 0.9981 & 33.5349 & 0.9968 & 0.1741 \\
\hline $\mathrm{CP}^{b)}$ & 0.8140 & 5.1248 & 0.9742 & 0.1309 & 0.9498 & 26.1885 & 0.9314 & 0.1435 \\
\hline $\mathrm{CP} 7^{b)}$ & 0.8915 & 5.4139 & 0.9994 & 0.1395 & 0.9849 & 26.9193 & 0.9828 & 0.1517 \\
\hline $\mathrm{CP}^{b)}$ & 0.9590 & 9.4288 & 0.9969 & 0.1774 & 0.9952 & 34.2542 & 0.9890 & 0.1623 \\
\hline $\mathrm{CP}^{a)}$ & 0.9179 & 5.1371 & 0.9989 & 0.1133 & 0.9930 & 25.2771 & 0.9854 & 0.1314 \\
\hline $\mathrm{CP} 10^{a)}$ & 0.9576 & 5.0860 & 0.9991 & 0.1015 & 0.9967 & 24.5469 & 0.9969 & 0.1222 \\
\hline $\left.\mathrm{CP} 11^{a}\right)$ & 0.9690 & 4.7286 & 0.9995 & 0.0838 & 0.9932 & 22.6482 & 0.9974 & 0.1057 \\
\hline
\end{tabular}

a) The pellets were coated with $2.5 \%$ coating level. $b$ ) The pellets were coated with $15 \%$ coating level.

Table 5. Kinetic Parameters of Pellets Coated with Various Coating Levels

\begin{tabular}{|c|c|c|c|c|c|c|c|c|c|}
\hline \multirow{2}{*}{$\begin{array}{l}\text { Formulation } \\
\text { code }\end{array}$} & \multirow{2}{*}{$\begin{array}{c}\text { Coating ratio } \\
(\%)\end{array}$} & \multicolumn{2}{|c|}{ Zero-order } & \multicolumn{2}{|c|}{ First-order } & \multicolumn{2}{|c|}{ Higuchi } & \multicolumn{2}{|c|}{ Hixson-Crowell } \\
\hline & & $R^{2}$ & $K$ & $R^{2}$ & $K$ & $R^{2}$ & $K$ & $R^{2}$ & $K$ \\
\hline \multirow[t]{4}{*}{ CP1 } & 0 & 0.9051 & 7.6731 & 0.9872 & 0.1946 & 0.9749 & 28.4005 & 0.9679 & 0.2171 \\
\hline & 2.5 & 0.8321 & 4.7978 & 0.9681 & 0.1145 & 0.9593 & 24.3707 & 0.9310 & 0.1294 \\
\hline & 5 & 0.9755 & 3.1856 & 0.9963 & 0.0437 & 0.9951 & 15.8600 & 0.9915 & 0.0606 \\
\hline & 7.5 & 0.9707 & 0.7271 & 0.9667 & 0.0077 & 0.9425 & 4.3629 & 0.9681 & 0.0117 \\
\hline \multirow[t]{8}{*}{ CP5 } & 0 & 0.9051 & 7.6731 & 0.9872 & 0.1946 & 0.9749 & 28.4005 & 0.9679 & 0.2171 \\
\hline & 2.5 & 0.9197 & 8.2151 & 0.9920 & 0.2058 & 0.9820 & 30.2727 & 0.9783 & 0.2300 \\
\hline & 5 & 0.9244 & 8.4589 & 0.9918 & 0.1904 & 0.9849 & 31.1370 & 0.9772 & 0.2213 \\
\hline & 7.5 & 0.9473 & 8.9540 & 0.9969 & 0.1830 & 0.9942 & 32.7131 & 0.9870 & 0.2200 \\
\hline & 10 & 0.9700 & 9.0207 & 0.9976 & 0.1716 & 0.9989 & 32.6460 & 0.9954 & 0.2115 \\
\hline & 12.5 & 0.9769 & 9.1384 & 0.9991 & 0.1632 & 0.9985 & 32.9475 & 0.9975 & 0.2057 \\
\hline & 15 & 0.9771 & 9.3038 & 0.9996 & 0.1570 & 0.9990 & 34.4199 & 0.9968 & 0.2019 \\
\hline & 17.5 & 0.9806 & 9.5083 & 0.9976 & 0.1571 & 0.9967 & 36.2137 & 0.9957 & 0.2035 \\
\hline
\end{tabular}

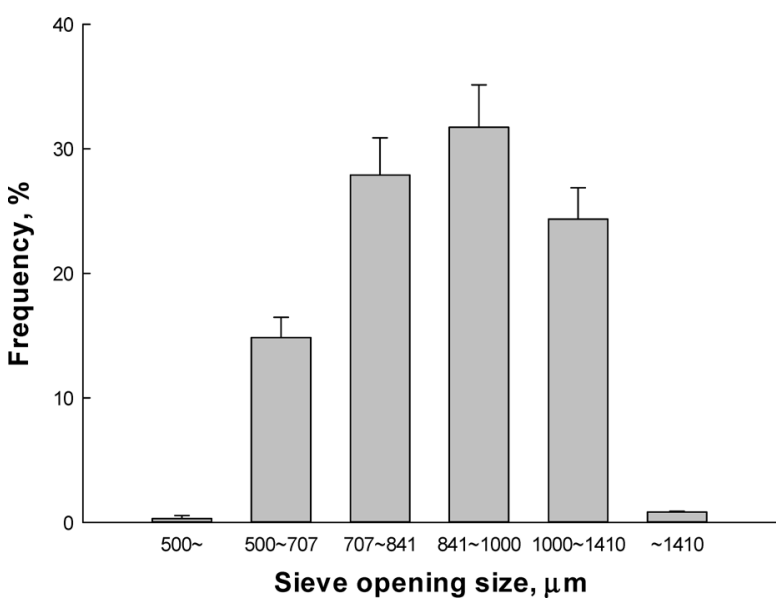

Fig. 1. The Size Distribution of the Core Pellets Containing $50 \%$ of MCC (Mean \pm S.D., $n=3$ )

It was due to poor solubility and swelling condition of MCC in water in comparison with lactose. When the pellets are exposed to water, MCC would swell and the pathway that drug moves through to be eluted would be longer. The core pellets containing 50\% MCC was chosen and used for the following experiments.
Effect of Coating Agents (Eudragit ${ }^{\circledR}$ RL/RS) and Coating Level on Dissolution Rate To acquire the sustained release profile of DXM pellets, Eudragit ${ }^{\circledR}$ RL PO or RS PO was used as a coating agent. The dissolution study of DXM pellets was performed to examine the effect of sustained release effect of Eudragit ${ }^{\circledR}$ RL PO and RS PO. The effect of the coating level on the dissolution rate was also evaluated since it could affect directly on dissolution rate of drug. Figure 4 shows dissolution profiles and kinetic constant of DXM from pellets coated with Eudragit ${ }^{\circledR}$ RL PO and RS PO by different coating level. The core pellets containing 50\% MCC were prepared for coating, and then the core pellets were coated from 2.5 to $17.5 \%$ coating level at $2.5 \%$ interval. In case of Eudragit $^{\circledR}$ RS PO, the coating level was from 2.5 to $7.5 \%$ because the dissolution rate of pellets coated with $7.5 \%$ coating level was too low. The release kinetic constants by kinetic equations were calculated and listed in Table 5. The release of coated pellets was most well fitted to first-order equation. The coated pellets prepared in the present study were small reservoir type, so the drug release from pellets could be determined by concentration gradient. As the result of the dissolution test for each formulation, the dissolution rate had slowed down gradually for both of Eudragit ${ }^{\circledR}$ RL PO and RS PO as the coating level had increased. However, there was a 


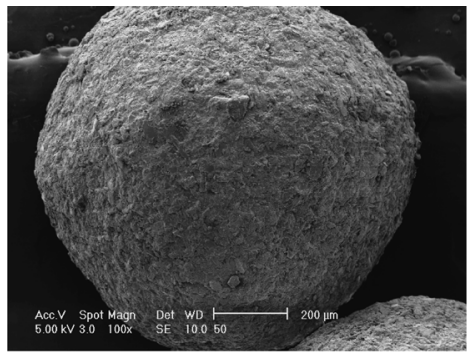

(a)

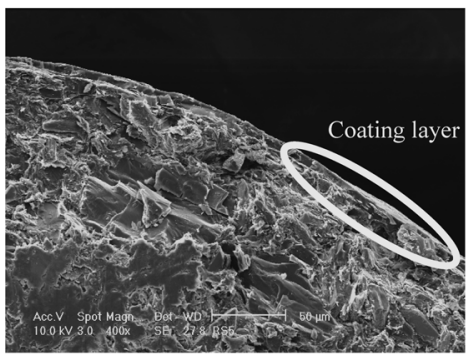

(c)

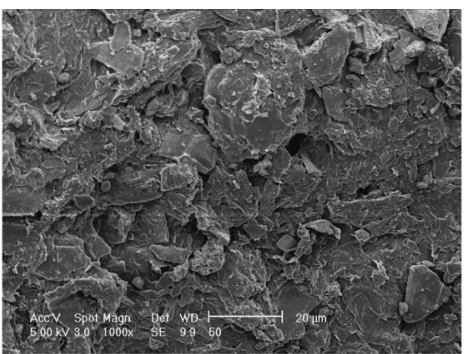

(b)

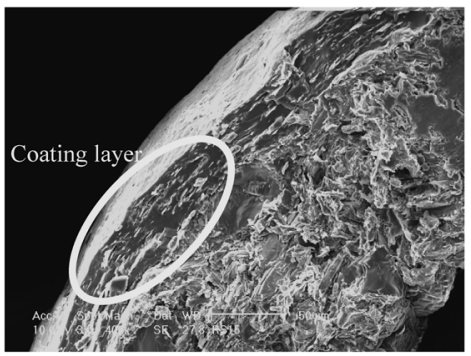

(d)

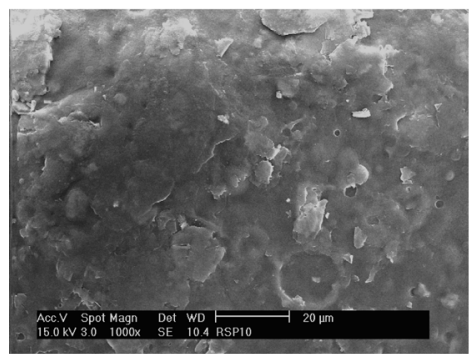

(e)

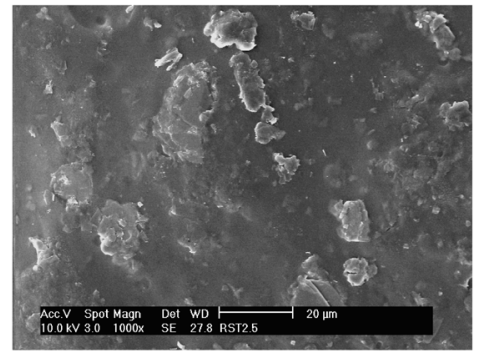

(f)

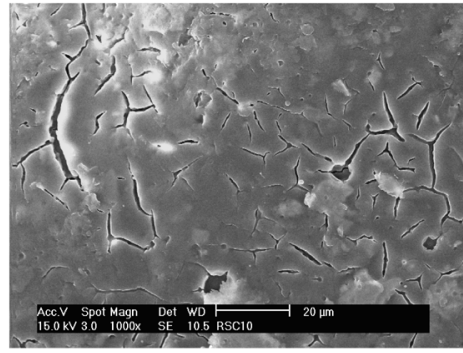

(g)

Fig. 2. Scanning Electron Micrographs of Representative DXM Pellets

(a) Core pellet containing $50 \% \mathrm{MCC}(\times 100)$; (b) surface of the pellet containing $50 \% \mathrm{MCC}(\times 1000)$; (c) cross-section of the pellet coated with $2.5 \%$ Eudragit ${ }^{\circledR}$ RS PO $(\times 400)$; (d) cross-section of the pellet coated with $17.5 \%$ Eudragit ${ }^{\circledR}$ RS PO $(\times 400)$; (e) PEG 6000 as a plasticizer $(\times 1000)$; (f) TEC as a plasticizer $(\times 1000)$; (g) castor oil as a plasticizer $(\times 1000)$.
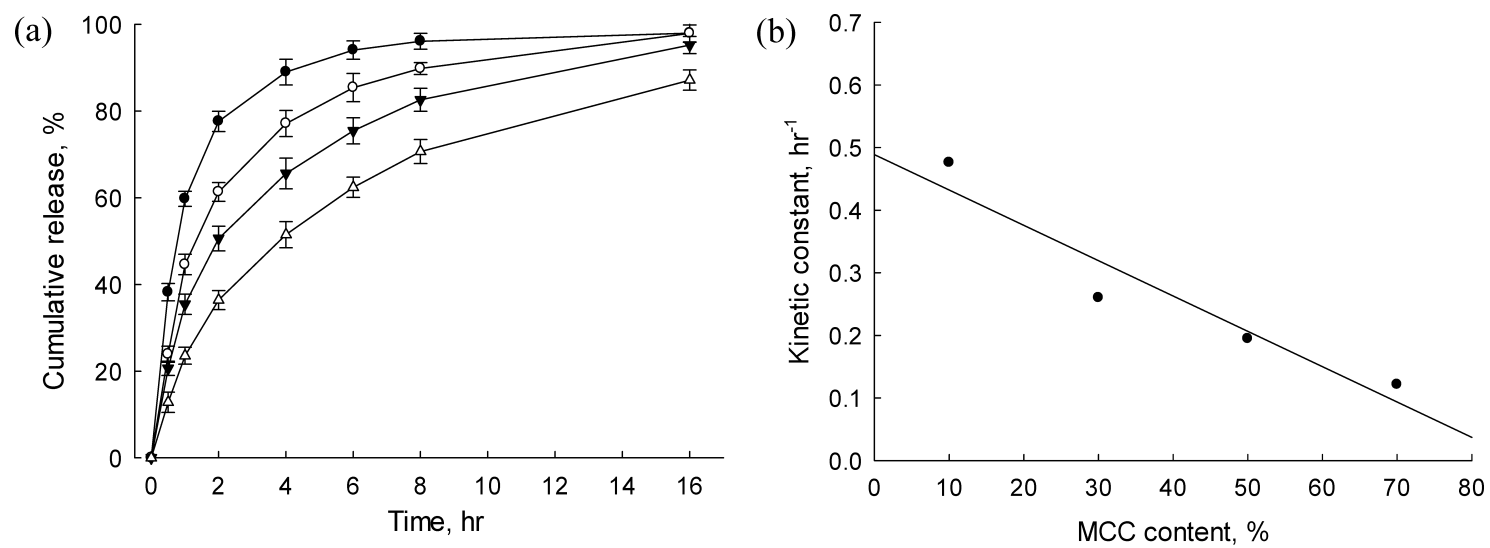

Fig. 3. The Effect of Amount of MCC in Core Pellets on Dissolution Rate of Doxazosin Mesylate

Dissolution profiles (a) and kinetic constant $k_{1}$ (b) of doxazosin mesylate core pellets containing different amount of MCC (mean \pm S.D., $n=3$ ). $\bullet, 10 \%$; O, $30 \%$; $\mathbf{\nabla}, 50 \%$; $\triangle, 70 \%$.

significant difference in the dissolution rate from Eudragit ${ }^{\circledR}$ RL PO and RS PO. The sustained-release effect of Eudragit ${ }^{\circledR}$ RS PO was much stronger than RL PO and the difference had increased distinctly as the coating level had increased (Fig. 4). Eudragit ${ }^{\circledR}$ RS PO had a slightly water permeable property, whereas, Eudragit ${ }^{\circledR}$ RL PO had a highly permeable characteristic. The differences of the effect on dissolution rate came from this distinction of property. In summary, dissolution rate of coated pellets had decreased as the coating level had increased. The pellets coated with Eudragit ${ }^{\circledR}$ RS PO were influenced strongly by coating level as compared to RL PO.

Effect of Various Plasticizer on Dissolution Rate In the 


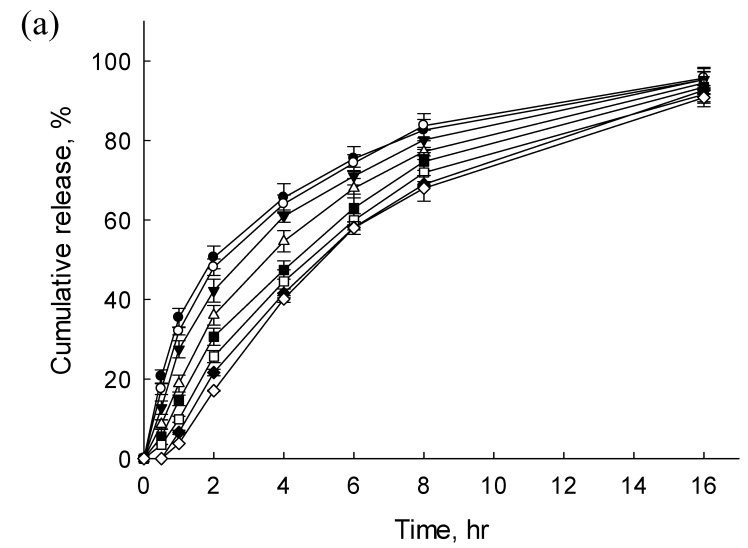

(c)

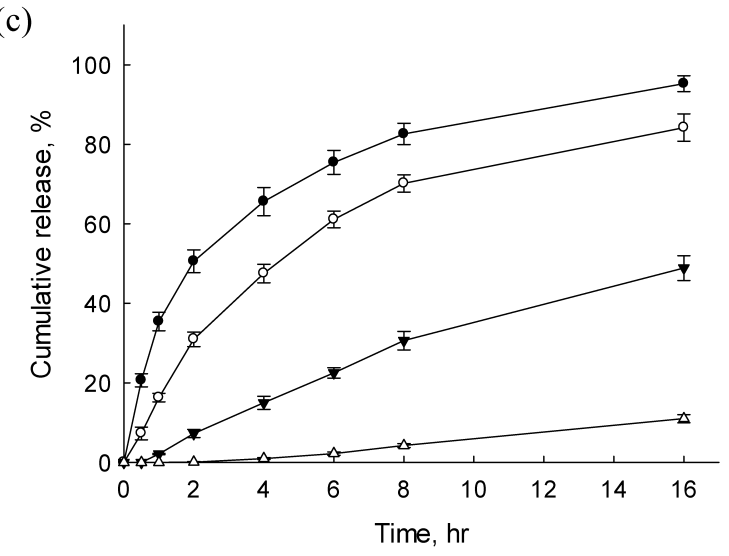

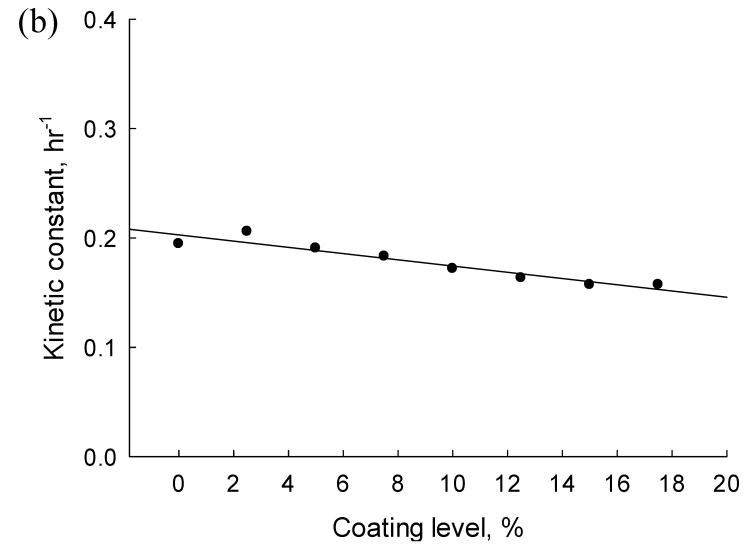

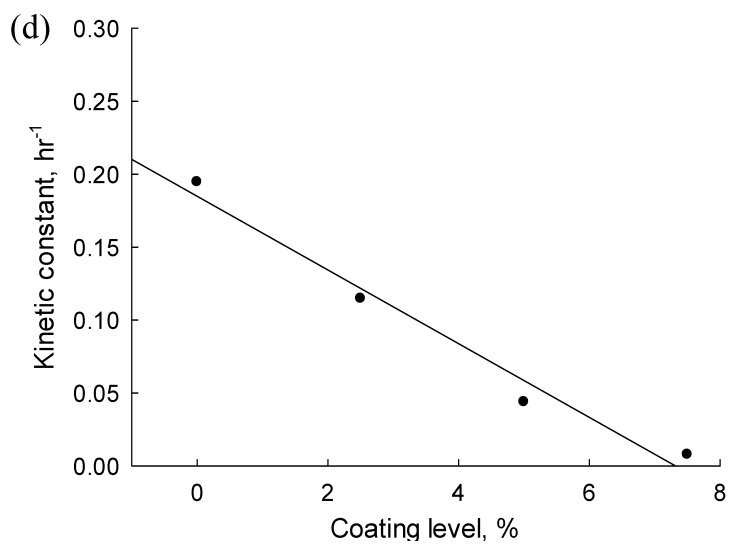

Fig. 4. The Effect of Coating Agent and Its Coating Level on Dissolution Rate of DXM from Pellets

Dissolution profile (a,c) and kinetic constant $k_{1}(\mathrm{~b}, \mathrm{~d})$ of coated pellets by different coating agents (a,b: Eudragit ${ }^{\circledR}$ RL PO; c, d: Eudragit ${ }^{\circledR}$ RS PO) and coating level (mean \pm S.D., $n=3$ ). $\bullet, 0 \% ; \bigcirc, 2.5 \% ; \nabla, 5 \% ; \triangle, 7.5 \% ; \square, 10 \% ; \square, 12.5 \% ; \diamond, 15 \% ; \diamond, 17.5 \%$.

coating process, plasticizer is required because most of the film forming polymers are brittle due to their complex structure. Plasticizers can enhance the flexibility and distensibility of the polymer by modifying the properties of the polymer. ${ }^{31)}$ The release of the drug from pellets would be sustained by the increased flexibility of coated films. ${ }^{32-34)}$ The plasticizers were classified into three groups, polyols (polyethylene glycols, propylene glycol), organic esters (triacetin, triethyl citrate, tributyl citrate) and fixed oils (castor oil). ${ }^{35)}$ Among them, PEG 6000 , TEC and castor oil, which represent each group, was selected in the present study. The selected plasticizers were widely used to enhance properties of coating film in coating process. $^{36-38)}$ The hydrophilicity of plasticizers could affect the dissolution rate of drug, so plasticizers were screened in accordance with the solubility in water. The hydrophilicity of plasticizers in water is increased in the sequence of castor oil, TEC, and PEG 6000. Core pellets were coated with coating dispersion containing $10 \%$ plasticizers based on polymer weight, and the effect of the plasticizers was examined with Eudragit $^{\circledR}$ RL PO and RS PO at a $15 \%$ and $2.5 \%$ coating level, respectively. In coated pellets with Eudragit ${ }^{\circledR}$ RL PO, the pellets showed a similar dissolution rate with the control group. It was thought that the hydrophilicity of plasticizers was less influenced to the release of drug because of the high permeable characteristic of Eudragit ${ }^{\circledR}$ RL PO. In the case of Eudragit $^{\circledR}$ RS PO coated pellets, in contrast with Eudragit ${ }^{\circledR}$ RL PO, the kind of plasticizers could affect the dissolution profile so there was a distinct profile difference from pellets without plasticizer (Fig. 5). In all formulations with plasticizers, the dissolution rate had decreased significantly. The pellets coated with TEC showed the slowest dissolution rate, on the other hand, those coated with PEG 6000 showed a moderate sustained effect. It was because of the differences of hydrophilicity, PEG 6000 is more soluble in water than TEC, so as less of a water soluble plasticizer, TEC, is more compatible with Eudragit ${ }^{\circledR}$ RS PO which is insoluble in water. As a result, the release of DXM from pellets coated with TEC was slower than PEG 6000. The pellets coated with castor oil were predicted to show a slower release rate than that of pellets coated with other plasticizers because of its low water soluble characteristic. However, in the present study, the pellets coated with castor oil showed similar release profile with PEG 6000 coated pellets. It is thought that castor oil had poor compatibility with Eudragit ${ }^{\circledR}$ RS PO in spite of its low hydrophilicity. As shown in Fig. 2, the cracks on the surface of pellets coated with castor oil were spotted, and it seemed that castor oil couldn't entirely work as a plasticizer. In conclusion, plasticizer could affect the dissolution rate of DXM pellets coated with Eudragit ${ }^{\circledR}$ RS PO, whereas in the case of Eudragit ${ }^{\circledR}$ RL PO coated pellets, plasticizer was a less important factor. PEG 6000 and TEC showed good ability as a plasticizer, however the pellets coated with TEC showed too much of a sustained drug release pattern.

According to the reference, a marketed product (Cardura $\mathrm{XL}^{\circledR}$, Pfizer) released $60 \%$ of DXM for $8 \mathrm{~h}$ in zero-order. ${ }^{39)}$ As shown in Fig. 5 b, 57 or $54 \%$ of DXM was released from 

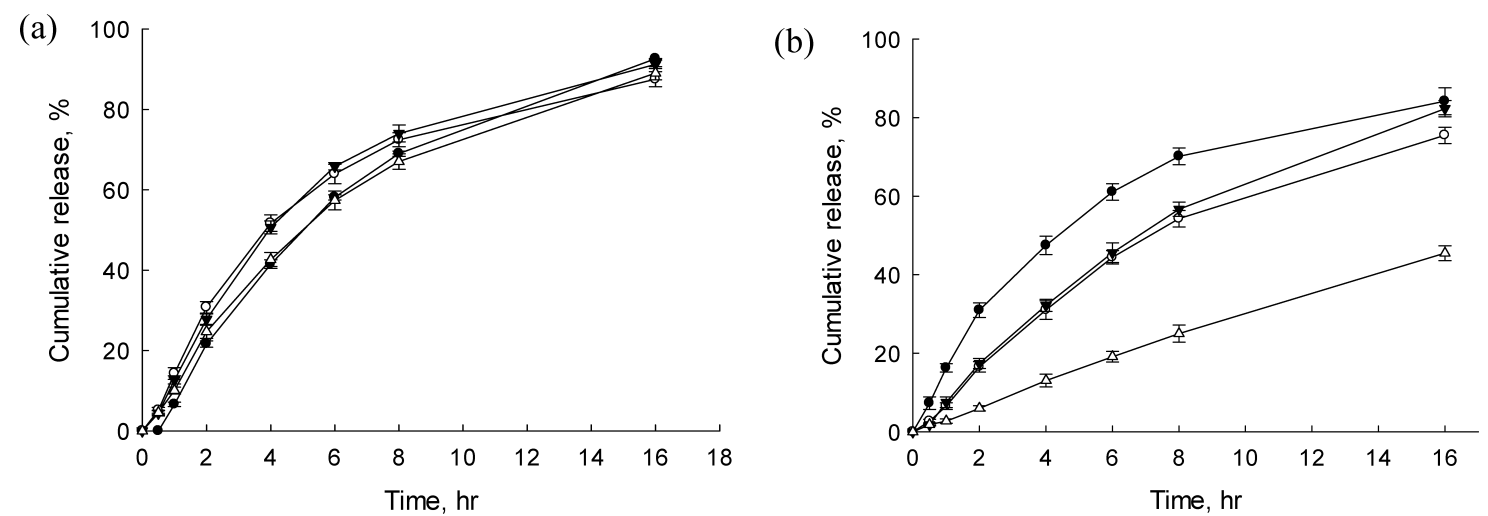

Fig. 5. The Effect of Various Plasticizers on Dissolution Rate from Pellets Coated with Eudragit ${ }^{\circledR}$ RL PO for $15 \%$ Coating Level (a) and Eudragit ${ }^{\circledR}$ RS PO for 2.5\% Coating Level (b) (Mean \pm S.D., $n=3$ )

$\bullet$, Control (no plasticizer); O, Castor oil; $\mathbf{\nabla}$, PEG 6000, $\triangle$, TEC.
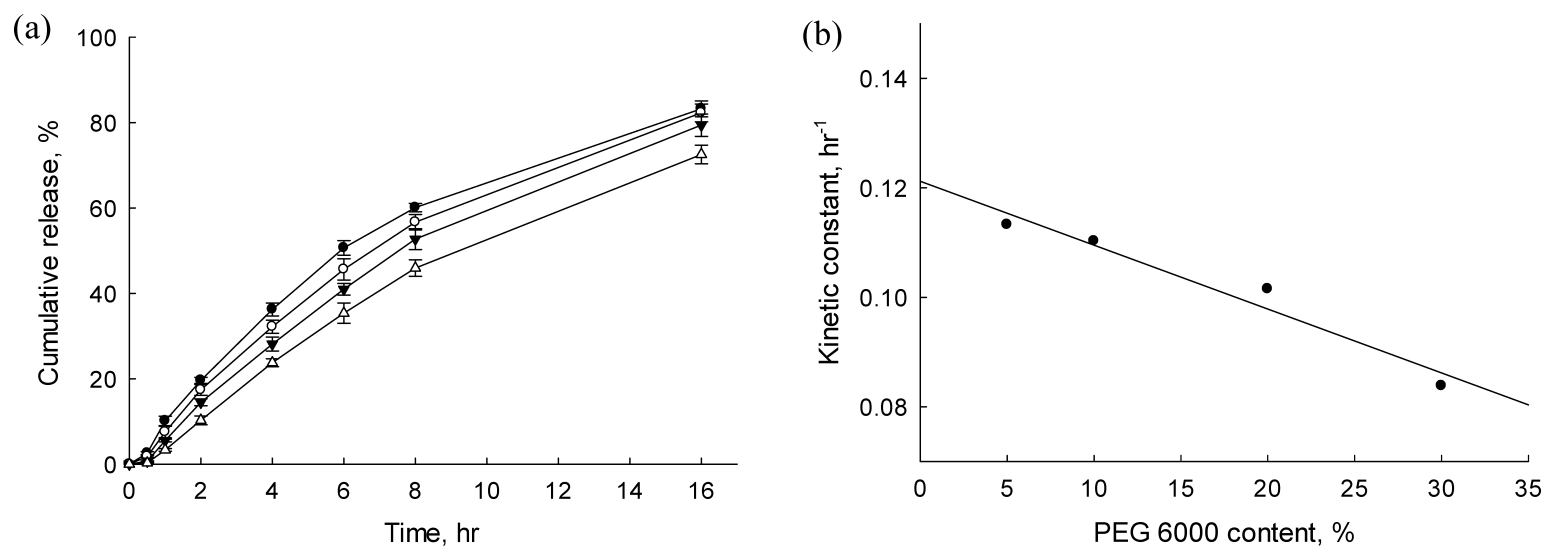

Fig. 6. The Effect of the Content of PEG 6000 on Dissolution Rate from Pellets Coated with Eudragit ${ }^{\circledR}$ RS PO for 2.5\% Coating Level

Dissolution profile (a) and kinetic constant $k_{1}$ (b) of coated pellets by different PEG 6000 amount were plotted (mean \pm S.D., $n=3$ ). $\bullet, 5 \% ; \bigcirc, 10 \% ; \mathbf{\nabla}, 20 \% ; \triangle, 30 \%$.

pellets with PEG 6000 or castor oil, respectively. However, pellets with castor oil showed trouble in coating integrity as given in Fig. $2 \mathrm{~g}$ and thus PEG 6000 was chosen as a plasticizer for further study.

Effect of Concentration of PEG 6000 on Dissolution

Rate The mechanical properties of both wet and dry films of Eudragit ${ }^{\circledR}$ RS PO could be significantly influenced by the concentration of plasticizer, because the plasticizer concentration affects both glass transition temperature $\left(T_{\mathrm{g}}\right)$ and the minimum film-forming temperature. ${ }^{40)}$ So, the effect of the plasticizer content ratio on release the of DXM was examined in the coated pellets with Eudragit ${ }^{\circledR}$ RS PO by $2.5 \%$ coating level. In the present study, PEG 6000 was used as plasticizer and coated pellets with the content ratio of $5,10,20$, and $30 \%$ based on polymer weight in coating dispersion were examined. The increasing concentration of plasticizers in coating solution generally shows decreased drug release profiles. ${ }^{35,41)}$

In the present study, similar results were obtained and presented in Fig. 6. The dissolution rate had decreased with an increase in the content ratio of PEG 6000 in coated pellets. It was also confirmed through the kinetic constant plotted by first-order equation. As the content ratio of PEG 6000 increased, the kinetic constant had decreased, gradually. It was considered due to the enhancement of the coalescence of the polymer, Eudragit ${ }^{\mathbb{B}}$ RS PO, by increasing the amount of plasticizer. ${ }^{40)}$ Increase of amount of PEG 6000 can cause either reduction of the release rate by enhancement of the coalescence of the polymer or enhancement of the release rate by water channeling effect. In the present study, dissolution rate decreased with increase in amount of PEG 6000, although PEG 6000 is a hydrophilic plasticizer. It was already reported that the coalescence of the polymer could be enhanced which lead to decrease in release rate when the low coating level was applied. ${ }^{42)}$ These results suggest that the contents of PEG 6000 could improve the coating condition by enhancing the flexibility of film and it had a mild sustained-release effect for DXM coated pellets with Eudragit ${ }^{\circledR}$ RS PO.

\section{Conclusion}

The sustained-release coated pellets containing DXM was prepared by extrusion-spheronization technique and fluid-bed coating method. The morphology of the pellets was evaluated by scanning electron microscopy. The prepared pellets were a regular spherical shape, and showed a uniform coating layer according to the coating level. The factors affecting properties of pellets such as MCC content in core pellets, coating agents, coating level and plasticizers were evaluated. Through this study, the following results were attained. As the content of MCC in pellets increased, the dissolution rate had decreased. The coating thickness is a very important factor to control the release of DXM from coated pellets and the effect on a sustained-release of Eudragit ${ }^{\circledR}$ RS PO is much higher, compared 
with Eudragit ${ }^{\circledR}$ RL PO. The plasticizer also could control the release of DXM from pellets coated with Eudragit ${ }^{\circledR}$ RS PO but the effect of plasticizers in Eudragit ${ }^{\circledR}$ RL PO is weaker as compared to Eudragit ${ }^{\circledR}$ RS PO. TEC appears to be of a notable low release profile compared with castor oil and PEG 6000 . In the case of castor oil, as a plasticizer, appears to have some problem which had cracks on the surface of coated pellets. Therefore, PEG 6000 is suitable for plasticizer because it appears to have a proper drug release profile and fine surface morphology of coating matrix. In conclusion, the pellets coated with Eudragit ${ }^{\circledR}$ RS PO and PEG 6000 would be appropriate for the sustained release DXM pellets, however, pharmacokinetic study for measurement of blood concentration should be performed to confirm the superiority of this system.

Acknowledgement This study was supported by Grant of the Korean Health Technology R\&D Project, for Health, Welfare \& Family Affairs, Republic of Korea (A092018). The authors are appreciated to Dalton Corp. for their instruments $\&$ technical supports.

\section{References}

1) Gillenwater J. Y., Conn R. L., Chrysant S. G., Roy J., Gaffney M., Ice K., Dias N., J. Urol., 154, 110-115 (1995).

2) Fulton B., Wagstaff A. J., Sorkin E. M., Drugs, 49, 295-320 (1995).

3) Lepor H., Kaplan S. A., Klimberg I., Mobley D. F., Fawzy A., Gaffney M., Ice K., Dias N., The Multicenter Study Group, J. Urol., 157, 525-530 (1997).

4) Alabaster V. A., Davey M. J., Br. J. Clin. Pharmacol., 21 (Suppl. 1), 9S-17S (1986).

5) Anegón M., Esteban J., Jiménez-García R., Sanz de Burgoa V., Martínez J., Gil de Miguel A., Clin. Ther., 24, 786-797 (2002).

6) Chung M., Vashi V., Puente J., Sweeney M., Meredith P., Br. J. Clin. Pharmacol., 48, 678-687 (1999).

7) Zhu Y., He H. C., Su T. W., Wu Y. X., Wang W. Q., Zhao J. P., Shen Z., Zhang C. Y., Rui W. B., Zhou W. L., Sun F. K., Ning G., Endocrine, 38, 254-259 (2010).

8) Pavli M., Vrečer F., Baumgartner S., Int. J. Pharm., 400, 15-23 (2010).

9) Katzhendler I., Hoffman A., Goldberger A., Friedman M., J. Pharm. Sci., 86, 110-115 (1997).

10) Nellore R. V., Rekhi G. S., Hussain A. S., Tillman L. G., Augsburger L. L., J. Controlled Release, 50, 247-256 (1998).

11) Bechgaard H., Nielsen G. H., Drug Dev. Ind. Pharm., 4, 53-67 (1978).

12) Eskilson C., Manufacturing Chemist, 56, 33-39 (1985).

13) Sellassie I. G., "Pharmaceutical Pelletization Technology," Marcel Dekker, New York, 1989, pp. 1-13.

14) Bechard S., Leroux J., Drug Dev. Ind. Pharm., 18, 1927-1944
(1992).

15) Vergote G. J., Vervaet C., Van Driessche I., Hoste S., De Smedt S., Demeester J., Jain R. A., Ruddy S., Remon J. P., Int. J. Pharm., 219, 81-87 (2001).

16) Michie H., Podczeck F., Newton J. M., Int. J. Pharm. 434, 175-182 (2012).

17) Goyanes A., Souto C., Martínez-Pacheco R., Eur. J. Pharm. Biopharm. 79, 658-663 (2011).

18) Alvarez L., Concheiro A., Gómez-Amoza J. L., Souto C., MartínezPacheco R., Eur. J. Pharm. Biopharm., 55, 291-295 (2003).

19) Bechgaard H., Brodie R. R., Chasseaud L. F., Houmøller P., Hunter J. O., Siklos P., Taylor T., Eur. J. Clin. Pharmacol., 21, 511-515 (1982).

20) Ghebre-Sellassie I., "Multiparticulate Oral Drug Delivery," Marcel Dekker, New York, 1994, p. 65.

21) Millili G., Schwartz J., Drug Dev. Ind. Pharm., 16, 1411-1426 (1990).

22) Aulton M., Dyer A., Khan K., Drug Dev. Ind. Pharm., 20, $3069-$ 3104 (1994).

23) Habib Y. S., Augsburger L. L., Shangraw R. F., Int. J. Pharm., 233, 67-83 (2002).

24) Franceschinis E., Bortoletto C., Perissutti B., Dal Zotto M., Voinovich D., Realdon N., Powder Technol., 207, 113-118 (2011).

25) Pérez J., Rabisková M., Int. J. Pharm., 242, 349-351 (2002).

26) Erceg M., Vertzoni M., Cerić H., Dumić M., Cetina-Cižmek B., Reppas C., Eur. J. Pharm. Biopharm. 80, $402-409$ (2012).

27) Najib N., Suleiman M., Drug Dev. Ind. Pharm., 11, 2169-2181 (1985).

28) Gibaldi M., Feldman S., J. Pharm. Sci., 56, 1238-1242 (1967).

29) Higuchi T., J. Pharm. Sci., 52, 1145-1149 (1963).

30) Hixson A., Crowell J., Ind. Eng. Chem., 23, 1160-1168 (1931).

31) Wang C.-C., Zhang G., Shah N. H., Infeld M. H., Waseem Malick A., McGinity J. W., Int. J. Pharm., 152, 153-163 (1997).

32) Goodhart F., Murthy K., Nesbitt R., Pharm. Tech., 8, 64-71 (1984).

33) Bodmeier R., Paeratakul O., Drug Dev. Ind. Pharm., 20, 1517-1533 (1994).

34) Hutchings D. E., Sakr A., J. Pharm. Sci., 83, 1386-1390 (1994).

35) Okarter T. U., Singla K., Drug Dev. Ind. Pharm., 26, 323-329 (2000).

36) Zhu Y., Shah N. H., Malick A. W., Infeld M. H., McGinity J. W., Int. J. Pharm., 241, 301-310 (2002).

37) Kibria G., Roni M. A., Absar M. S., Jalil R. U., AAPS PharmSciTech, 9, 1240-1246 (2008).

38) Khan Z. A., Tripathi R., Mishra B., AAPS PharmSciTech, 12, 1-12 (2011).

39) Cha K. H., Tran T. H., Kim M. S., Kim J. S., Park H. J., Park J., Cho W., Hwang S. J., Arch. Pharm. Res., 33, 2003-2009 (2010).

40) Kojima M., Nakagami H., J. Controlled Release, 82, 335-343 (2002).

41) Bando H., McGinity J. W., Int. J. Pharm., 323, 11-17 (2006).

42) Bodea A., Leucuta S. E., Int. J. Pharm., 154, 49-57 (1997). 